\title{
Risk of secondary cancers from scattered radiation during intensity-modulated radiotherapies for hepatocellular carcinoma
}

\author{
Dong Wook Kim¹, Kwangzoo Chung², Weon Kuu Chung', Sun Hyun Bae', Dong Oh Shin ${ }^{3}$, Seongeon Hong ${ }^{3}$, \\ Sung Ho Park ${ }^{4}$, Sung-Yong Park ${ }^{5}$, Chae-Seon Hong ${ }^{2}$, Young Kyung Lim ${ }^{6}$, Dongho Shin ${ }^{6}$, Se Byeong Lee ${ }^{6}$, \\ Hyun-ho Lee ${ }^{7}$, Jiwon Sung ${ }^{7}$ and Myonggeun Yoon ${ }^{7 *}$
}

\begin{abstract}
Purpose: To evaluate and compare the risks of secondary cancers from therapeutic doses received by patients with hepatocellular carcinoma (HCC) during intensity-modulated radiotherapy (IMRT), volumetric arc therapy (VMAT), and tomotherapy (TOMO)

Methods: Treatments for five patients with hepatocellular carcinoma (HCC) were planned using IMRT, VMAT, and TOMO. Based on the Biological Effects of lonizing Radiation VII method, the excess relative risk (ERR), excess absolute risk (EAR), and lifetime attributable risk (LAR) were evaluated from therapeutic doses, which were measured using radiophotoluminescence glass dosimeters (RPLGDs) for each organ inside a humanoid phantom.
\end{abstract}

Results: The average organ equivalent doses (OEDs) of 5 patients were measured as $0.23,1.18,0.91,0.95,0.97,0.24$, and 0.20 Gy for the thyroid, lung, stomach, liver, small intestine, prostate (or ovary), and rectum, respectively. From the OED measurements, LAR incidence were calculated as 83, 46, 22, 30, 2 and 6 per $10^{4}$ person for the lung, stomach, normal liver, small intestine, prostate (or ovary), and rectum.

Conclusions: We estimated the secondary cancer risks at various organs for patients with HCC who received different treatment modalities. We found that HCC treatment is associated with a high secondary cancer risk in the lung and stomach.

Keywords: HCC, IMRT, VMAT, Tomotherapy, Radiophotoluminescence, OED, EAR, ERR, LAR

\section{Introduction}

Hepatocellular carcinoma (HCC), the most common primary cancer of the liver, is a malignant disease that causes death within a few months, unless it is treated appropriately $[1,2]$. Surgical resection is the standard treatment for HCC, but approximately $80 \%$ of cases are unresectable, generally because of preexisting hepatic dysfunction associated with cirrhosis or the multifocality of its presentation [3]. Transcatheter arterial chemoembolization (TACE), percutaneous ablation $[4,5]$, and radiation therapy (RT) [6,7] have been used for patients with unresectable $\mathrm{HCC}$, but the standard treatment

\footnotetext{
* Correspondence: radioyoon@gmail.com

${ }^{7}$ Department of Radiological Science, College of Health Science, Korea University, Jeongneung 3-dong, Seongbuk-gu, Seoul, Korea Full list of author information is available at the end of the article
}

modality for primary HCC has not yet been established. Only TACE has been proven to provide a survival benefit in a phase III study of advanced-stage disease [8]. In the past, the role of RT for HCC has been limited because of the low tolerance of the liver to RT and the risks of radiation-induced liver disease [9]. However, RT treatments have tended to shift from palliative to cure-oriented therapies with each new development in RT techniques, such as intensity-modulated radiotherapy (IMRT) [10-16] (including volumetric-modulated arc therapy $[17,18])$, helical tomotherapy (TOMO) [19-24] and particle therapy [25-27].

When tumors are exposed to the high doses that are prescribed for a definitive or palliative goal, the surrounding normal tissues are generally exposed to intermediate doses because of the primary radiation in the 
beam path. Therefore, the treatment planning is optimized to identify the option that best satisfies two conflicting priorities: reducing the dose that the surrounding normal organ is exposed to, and focusing the prescription dose into a target volume. However, out-of-field exposure is another issue of concern; during radiation treatment, the rest of the body is also exposed to low doses because therapeutic radiation in out-of-field region where is all tissues without the trans-axial planed of PTV. Therefore, it is also important to measure the exposed dose for normal organs in out-of-field regions, as well as the corresponding cancer risk.

To date, there have been many measurements of secondary scattered dose and many assessments of secondary cancer risk [28-34]. These studies reflect concerns that the secondary cancer risk may be increased by IMRT compared with that by 3D-CRT because IMRT uses more fields and monitor units, which cause a higher wholebody exposure to leakage radiation. It has been reported that IMRT induces almost twice the incidence of second malignancies that is associated with 3D-CRT [28-34]. Yoon et al. have investigated the secondary scattered radiation doses of IMRT and proton therapy for patients with lung and liver cancer [31]. They presented secondary scattered dose measurements for IMRT at $20-50 \mathrm{~cm}$ from the isocenter, which ranged from 5.8 to $1.0 \mathrm{mGy}$ per $1 \mathrm{~Gy}$ of the target volume dose (Gray [Gy] is the SI unit of therapeutic absorbed dose). In a previous study, we reported organ equivalent dose (OED) measurements for patients with stage III non-small cell lung cancer [30]. The mean values of the relative OEDs of secondary doses from VMAT and TOMO, which were normalized by IMRT, ranged from $88.63 \%$ to $41.59 \%$.

In this study, we compared the risks of secondary cancer from out-of-field and in-field radiation for three treatment modalities, using the concept of OED for radiation-induced cancer in patients with primary HCC.

\section{Methods and materials}

\section{Patient data and treatment planning}

We randomly selected five HCC patients who were to be treated with double arc VMAT at Kyunghee University Hospital, Gangdong. Each of these patients had undergone treatment planning computed tomography (CT) (Brilliance CT Big Bore Oncology; Philips Medical System,
Amsterdam, The Netherlands) to identify targets and normal neighboring organs. Eclipse (Varian Medical Systems, Palo Alto, CA, USA) and Hi-Art (TomoTherapy, Madison, WI, USA) planning systems were used to plan IMRT, VMAT, and TOMO for these patients. As shown in Table 1, the patient group consisted of four male patients and one female patient. The ages of the patients ranged from 42 to 62 years, with a mean age of 53 years. All patients had primary $\mathrm{HCC}$ with a single target, and planning target volumes (PTVs) varied from 60 to $2112 \mathrm{cc}$.

The targets were defined in accordance with Report 50 of the International Commission on Radiation Units and Measurements (ICRU 50). A four-dimensional CT (4DCT) image was obtained during the CT scan using a Philips Brilliant Big Bore CT with a Varian real-time patient monitoring system (RPMS). Particularly, the gross tumor volume (GTV) encompassed all detectable tumors that were observed in the CT scans. The clinical target volume (CTV) included the GTV with a margin for the micro tumor-cell region. The planning target volume (PTV) included the CTV plus a 7-10 mm margin. Each patient received a total dose of 52.5-72.0 Gy to the PTV (using different fractionation schemes) at the isocenter. The prescribed dose was specified at the ICRU reference point (isocenter) of the PTV. All treatment plans used eight beams for IMRT, double arcs for VMAT, and a helical beam for TOMO. $10 \mathrm{MV}$ beam was used for IMRT and VMAT, and $6 \mathrm{MV}$ beam was used for TOMO planning. Examples of the plans are presented in Figure 1, which shows patient 1's treatment plans for each of the modalities (IMRT, VMAT, and TOMO).

\section{Calibration of the radiophotoluminescence glass dosimeter}

In this study, we used a commercially available radiophotoluminescence glass dosimeter (RPLGD; GD-302 M, Asahi Techno Glass Co., Japan) for dose measurements [35-37]. For these RPLGDs, the absorbed dose was proportional to the light signal $(500-700 \mathrm{~nm})$ from the irradiated dosimeter when it was exposed to $365-\mathrm{nm}$ mono-energetic laser light. At energies $>200 \mathrm{keV}$, RPLGDs have a reliable reproducibility of approximately $1 \%$ and relatively low energy dependency compared with themoluminescence dosimeters (TLDs) [35-37]. In addition, RPLGDs have a relatively small incident-beam angular

\section{Table 1 Patient information}

\begin{tabular}{|c|c|c|c|c|c|c|}
\hline ID & Sex & Age & Disease & Stage & PTV volume (cc) & Prescription dose (Gy) \\
\hline 1 & Male & 62 & $\mathrm{HCC}$ & III & 483 & 55.0 \\
\hline 2 & Male & 54 & $\mathrm{HCC}$ & I & 60 & 66.0 \\
\hline 3 & Male & 59 & $\mathrm{HCC}$ & III & 421 & 52.5 \\
\hline 4 & Female & 49 & $\mathrm{HCC}$ & IV & 2112 & 60.0 \\
\hline 5 & Female & 42 & $\mathrm{HCC}$ & IV & 214 & 72.0 \\
\hline
\end{tabular}




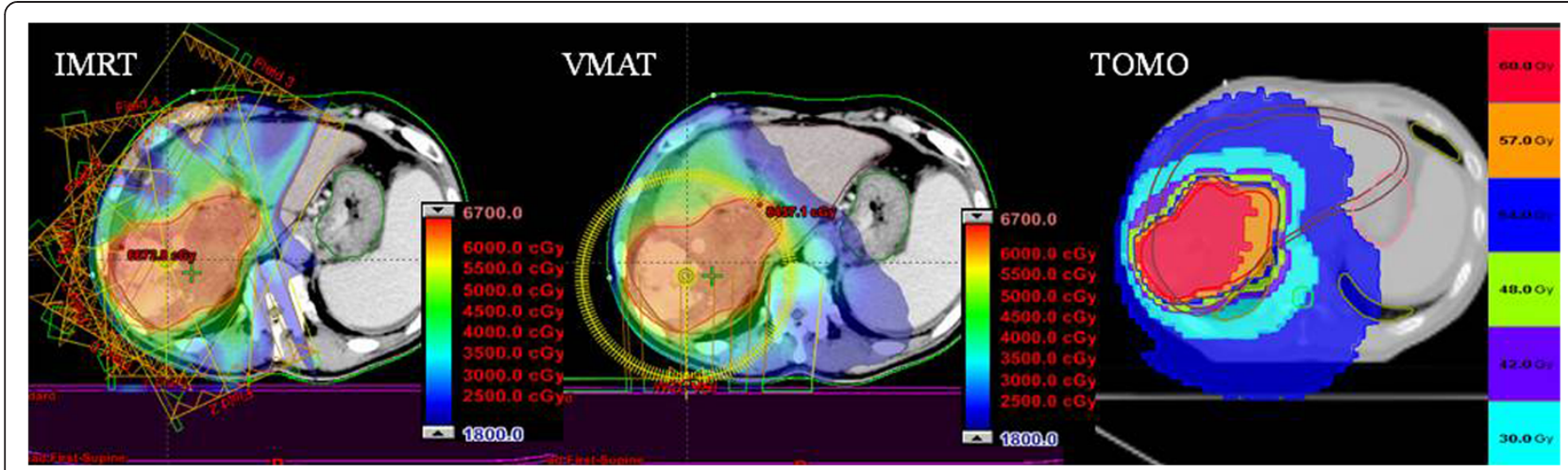

Figure 1 Patient 4's dose distribution for different modalities: IMRT, VMAT, and TOMO. The prescription dose was 62.5 Gy in 25 fractions.

dependency and a low toxicity inside the human body compared with TLDs or optically stimulated luminescence dosimeters (OSLDs) [38-40]. Our RPLGDs had a rod-like shape with a diameter of $1.5 \mathrm{~mm}$ and a length of $8.5 \mathrm{~mm}$.

RPLGDs were calibrated by measuring the response of each detector after being exposed to a $10 \times 10 \mathrm{~cm}^{2}$ open field photon beam at the depth of the maximum dose in water-equivalent solid phantom, with a $100-\mathrm{cm}$ sourceto-surface distance (SSD) and the absorbed dose at the calibration point was sat as 1 cGy per one monitor units (MU). The reproducibility of the RPLGDs was estimated by calculating the standard deviation of dose measurements that were taken when the same detector was exposed to the photon beam three times. Additionally, the deviations of each RPLGD detector were measured to characterize the RPLGDs.

\section{Measurement of therapeutic dose during IMRT, VMAT, and Tomotherapy treatment}

The treatment beams for IMRT, VMAT, and TOMO were delivered to the humanoid phantom (RANDO ${ }^{\circ}$ Phantom; The Phantom Laboratory, Salem, NY, USA) using the same patient setup, and the PTV exposure dose was set at $10 \mathrm{~Gy}$. Therapeutic radiation at in-field/out-of-field was assessed by measuring the dose in the RPLGDs at each organ inside the humanoid phantom. These measurements were performed using two to four RPLGDs set in the humanoid phantom at the location of the thyroid, small intestine, prostate/ovary, and rectum, as presented in Figure 2. For the organs adjacent to the PTV (lung, stomach, and normal liver), the doses were estimated using the dose-volume histograms (DVH) of each treatment plan, instead of being measured with RPLGDs. For the accuracy of dos calculation of ECLIPS Analytical Anisotropic Algorithm (AAA) [41,42] and TOMO Hi-Art $[43,44]$, several previous studies report less than $3 \%$ of uncertainty in dose calculation in-field region. Some studies reported the our-of-field dose calculation around 50\% where the region of iso-dose is less than 10\% [45-47]. Therefore, the uncertainty of dose in DVH of the stomach and normal liver were less than 3\% because most of volume of these organs covered large than $10 \%$ of prescription dose but the uncertainty of lung dose could be large as $50 \%$ of organ dose.

\section{Cancer incidence risk estimation attributable to secondary doses}

The lifetime attributable risk (LAR) of incidence for a person who is exposed to radiation dose $D$ at age $e$, can be expressed as below (based on the Biological Effects of Ionizing Radiation [BEIR] VII report),

$$
L A R(D . e)=\int_{e+L}^{100} M(D, e, a) \times S(a) / S(e) d a
$$

where $M(D, e, a)$ is the excess absolute risk at attained age $a$ from exposed age $e, \mathrm{~S}(a) / \mathrm{S}(e)$ is the ratio of the probability of surviving at age $a$ and $e$, and $\mathrm{L}$ is the latent period ( $5 \mathrm{y}$ for solid cancers) (National Research Council 2006).

The excess absolute risk (EAR) and excess relative risk (ERR) are modeled according to BEIR VII as functions of sex, age at exposure, and attained age, as below,

$$
\operatorname{EAR}(x, e, a) \operatorname{or} E R R(x, e, a)=\beta_{s} D \exp (\gamma e *)(a / 60)^{\eta}
$$

where $\beta, \gamma, \eta$ are model parameters, $e$ is the age at exposure, $e^{*}=(\min (e, 30)-30) / 10$ and $a$ is the attained age. The attained age was arbitrarily set at $20 \mathrm{y}$ after exposure. Table 2 shows the parameter values for preferred risk models in BEIR VII (National Research Council 2006). EAR and ERR of the small intestine were calculated by using the parameters of the colon in Table 2 . 


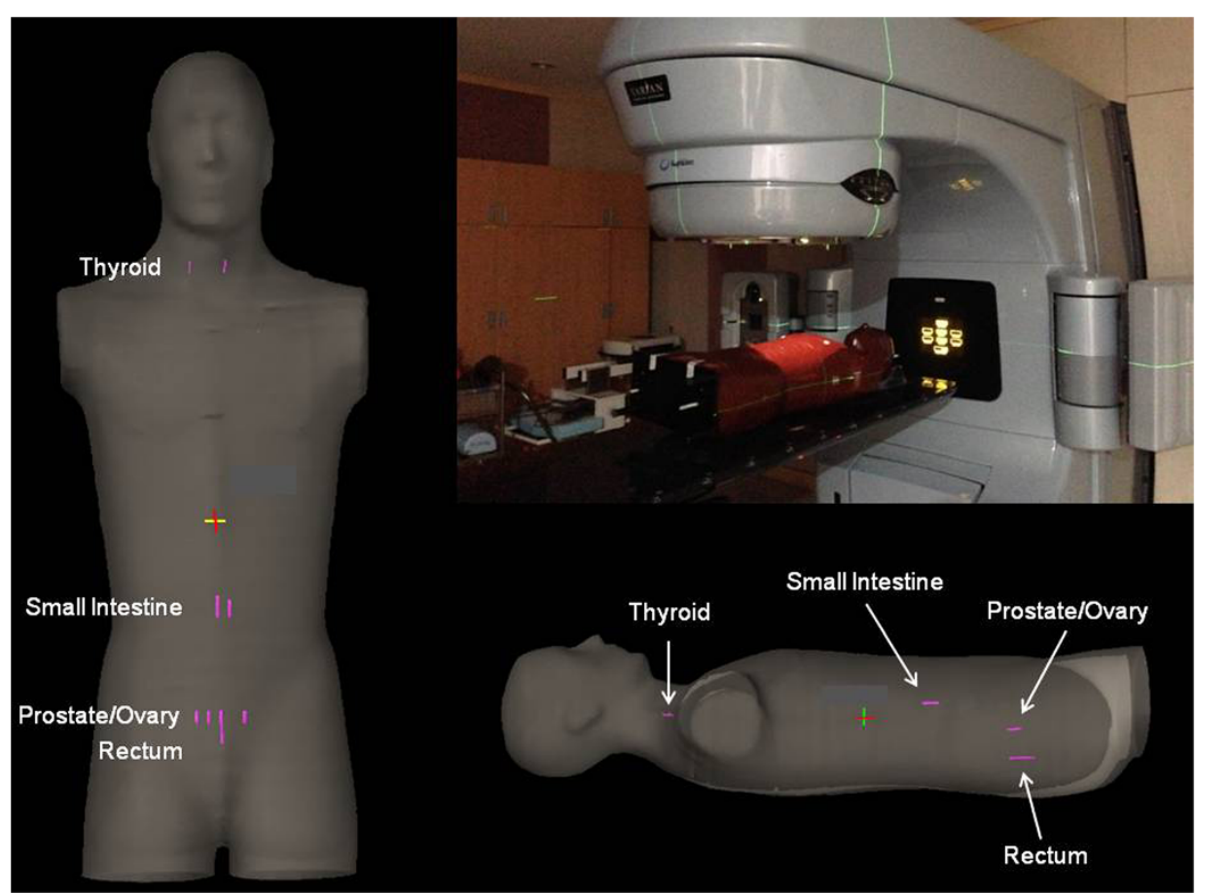

Figure 2 The setup for the therapeutic dose measurement with a humanoid phantom. To measure the organ doses in the out-of-field region, two or three RPLGDs were inserted at the positions of interesting organs inside the humanoid phantom: the thyroid, small intestine, prostate/ovary, and rectum.

The organ equivalent dose (OED) calculation was based on a plateau dose-response model, and is inserted as $\mathrm{D}$ in equation (2) and expressed as below,

$$
O E D=\frac{1}{V} \sum_{i} V_{i}\left(\frac{1-\exp \left(-\delta D_{i}\right)}{\delta}\right)
$$

where $V$ is the whole volume, $V_{i}$ is a volume element, and $D_{i}$ is the absorbed dose element. In this model, parameters such as $\delta$ are used to determine the doseresponse curve for specific organs, as presented in Table 3.

Table 2 Parameters for preferred risk incidence models in BEIR VII

\begin{tabular}{|c|c|c|c|c|c|c|c|c|}
\hline \multirow[t]{2}{*}{ Cancer } & \multicolumn{4}{|c|}{ ERR model } & \multicolumn{4}{|c|}{ EAR model } \\
\hline & $\beta_{M}$ & $\beta_{F}$ & $\gamma$ & $\eta$ & $\beta_{M}$ & $\beta_{F}$ & $\gamma$ & $\eta$ \\
\hline Thyroid & 0.53 & 1.05 & -0.83 & 0.00 & \multicolumn{4}{|c|}{ Not used } \\
\hline Lung & 0.32 & 1.40 & -0.30 & -1.40 & 2.30 & 3.40 & -0.41 & 5.20 \\
\hline Stomach & 0.21 & 0.48 & -0.30 & -1.40 & 4.90 & 4.90 & -0.41 & 2.80 \\
\hline Liver & 0.32 & 0.32 & -0.30 & -1.40 & 2.20 & 1.00 & -0.41 & 4.10 \\
\hline Colon & 0.63 & 0.43 & -0.30 & -1.40 & 3.20 & 1.60 & -0.41 & 2.80 \\
\hline Bladder & 0.50 & 1.65 & -0.30 & -1.40 & 1.20 & 0.75 & -0.41 & 6.00 \\
\hline Prostate & 0.12 & - & -0.30 & -1.40 & 1.20 & - & -0.41 & 2.80 \\
\hline Ovary & - & 0.38 & -0.30 & -1.40 & - & 0.70 & -0.41 & 2.80 \\
\hline
\end{tabular}

${ }^{\mathrm{a}}$ From Table Twelve-Two (National Research Council 2006).
In this study, we have investigated the OED based cancer incidence risk. The doses and cancer risks were evaluated for thyroid, lung, stomach, normal liver, small intestine, prostate/Ovary and rectum which were provided the parameter values for calculation by preferred risk models in BEIR VII.

\section{Results and discussion}

Table 4 compares the treatment plans for different modalities. For IMRT, eight fields were used. For all fields in each IMRT plan, the total monitor units (MU) per single Gy to the PTV ranged from 312 to $722 \mathrm{MU} / \mathrm{Gy}$. For VMAT, two full arcs were used. For all fields in each VMAT plan, the total MU per single Gy to the PTV ranged from 291 to $346 \mathrm{MU} / \mathrm{Gy}$. For the TOMO plans, the total MU per single Gy to the PTV ranged from 534 to $1865 \mathrm{MU} / \mathrm{Gy}$. More MUs were needs for larger PTV size for IMRT and TOMO but MU of VMAT was not depended significantly for PTV size. Therefore, patient 2 (patient 4) had a relatively lower (higher) MU per Gy than the other patients did, as is evident in Table 4. In addition, the value of MU per Gy depends on the modality. VMAT had a relatively small amount of total treatment MUs $(0.7 \pm 0.2$ times that of IMRT $)$ and no significant dependency with PTV size. TOMO had a comparably large amount of treatment MUs $(1.8 \pm 0.5$ times that of IMRT). As reported in previous studies, VMAT uses less MUs than IMRT and TOMO. Therefore, 
Table 3 Organ equivalent dose (Gy) per prescription dose at each organ

\begin{tabular}{|c|c|c|c|c|c|c|c|}
\hline Organ & $\delta$ & Modality IID & 1 & 2 & 3 & 4 & 5 \\
\hline \multirow[t]{3}{*}{ Thyroid } & 0.69 & IMRT & 0.21 & 0.09 & 0.28 & 0.55 & 0.17 \\
\hline & & VMAT & 0.15 & 0.08 & 0.23 & 0.47 & 0.17 \\
\hline & & TOMO & 0.18 & 0.14 & 0.19 & 0.40 & 0.11 \\
\hline \multirow[t]{3}{*}{ Lung } & 0.15 & IMRT & 0.13 & 0.07 & 0.18 & 2.59 & 0.25 \\
\hline & & VMAT & 0.13 & 0.08 & 0.20 & 2.87 & 0.31 \\
\hline & & TOMO & 1.72 & 1.65 & 2.37 & 3.27 & 1.89 \\
\hline \multirow[t]{3}{*}{ Stomach } & 1.20 & IMRT & 0.83 & 0.82 & 0.83 & 0.83 & 1.08 \\
\hline & & VMAT & 0.83 & 0.83 & 0.83 & 0.83 & 1.73 \\
\hline & & TOMO & 0.83 & 0.83 & 0.83 & 0.83 & 0.83 \\
\hline \multirow[t]{3}{*}{ Normal liver } & 1.14 & IMRT & 0.83 & 0.72 & 0.83 & 0.80 & 1.69 \\
\hline & & VMAT & 0.83 & 0.72 & 0.83 & 0.83 & 1.74 \\
\hline & & TOMO & 0.88 & 0.86 & 0.88 & 0.88 & 0.88 \\
\hline \multirow[t]{3}{*}{ Small intestine } & 0.26 & IMRT & 0.67 & 0.26 & 0.88 & 2.04 & 0.48 \\
\hline & & VMAT & 0.63 & 0.29 & 0.90 & 2.03 & 0.69 \\
\hline & & TOMO & 0.70 & 0.21 & 0.88 & 3.51 & 0.41 \\
\hline \multirow[t]{3}{*}{ Prostate/Ovary } & 0.73 & IMRT & 0.25 & 0.13 & 0.25 & 0.59 & 0.18 \\
\hline & & VMAT & 0.19 & 0.07 & 0.24 & 0.48 & 0.17 \\
\hline & & TOMO & 0.21 & 0.08 & 0.22 & 0.44 & 0.14 \\
\hline \multirow[t]{3}{*}{ Rectum } & 0.26 & IMRT & 0.18 & 0.08 & 0.22 & 0.51 & 0.14 \\
\hline & & VMAT & 0.15 & 0.06 & 0.18 & 0.41 & 0.15 \\
\hline & & TOMO & 0.17 & 0.06 & 0.16 & 0.40 & 0.12 \\
\hline
\end{tabular}

Table 4 Treatment planning information

\begin{tabular}{lccc}
\hline ID & Modality & \# of fields (or arcs) & MU/Gy \\
\hline $\mathbf{1}$ & IMRT & 8 & 543 \\
& VMAT & 2 & 291 \\
$\mathbf{2}$ & TOMO & $\mathrm{n} / \mathrm{a}$ & 907 \\
& IMRT & 8 & 312 \\
& VMAT & 2 & 346 \\
$\mathbf{3}$ & TOMO & $\mathrm{n} / \mathrm{a}$ & 534 \\
& IMRT & 8 & 597 \\
& VMAT & 2 & 345 \\
$\mathbf{4}$ & TOMO & $\mathrm{n} / \mathrm{a}$ & 717 \\
& IMRT & 8 & 722 \\
& VMAT & 2 & 317 \\
& TOMO & $\mathrm{n} / \mathrm{a}$ & 1865 \\
$\mathbf{5}$ & IMRT & 8 & 384 \\
& VMAT & 2 & 304 \\
& TOMO & $\mathrm{n} / \mathrm{a}$ & 776 \\
\hline
\end{tabular}

VMAT facilitates shorter treatment times and fewer MUs that are related to patient immobilization and machine maintenance $[30,48,49]$.

For each of the five patients, Table 5 presents the dose measurements for IMRT, VMAT, and TOMO in the infield and out-of-field regions. In-field region is assigned as all tissue within the trans-axial planes of PTV. The mean doses per 1 Gy of therapeutic dose at the thyroid, lung, stomach, normal liver, small intestine, prostate (or ovary), and rectum were $0.5,3.9,23.6,36.3,1.8,0.6$, and $0.4 \mathrm{cGy} / \mathrm{Gy} \mathrm{Rx}_{\mathrm{Rx}}$ for IMRT; 0.4, 4.2, 28.2, 36.9, 1.9, 0.4, and $0.3 \mathrm{cGy} / \mathrm{Gy}_{\mathrm{Rx}}$ for VMAT; and 0.4, 8.8, 37.0, 40.4, 4.0, 0.4, and $0.3 \mathrm{cGy} / \mathrm{Gy}_{\mathrm{Rx}}$ for TOMO, respectively. (Means were taken over the five patients). The measured dose decreased as the distance from the in-field region increased, and increased as the size of PTV. Therefore, patient 2 who have most of small PTV size, gives relatively small measured dose for all organs as shown in Table 5. For the in-field region, the PTV position is also

Table 5 The absorbed dose per 1 Gy of therapeutic dose at each organ

\begin{tabular}{|c|c|c|c|c|c|c|}
\hline \multirow[t]{2}{*}{ Organ } & \multirow[t]{2}{*}{ Modality IID } & \multicolumn{5}{|c|}{ Organ dose per $1 \mathrm{~Gy}$ (cGy/Gy) } \\
\hline & & 1 & 2 & 3 & 4 & 5 \\
\hline \multirow[t]{3}{*}{ Thyroid } & IMRT & 0.4 & 0.1 & 0.6 & 1.1 & 0.3 \\
\hline & VMAT & 0.3 & 0.1 & 0.5 & 0.9 & 0.3 \\
\hline & TOMO & 0.4 & 0.2 & 0.4 & 0.8 & 0.2 \\
\hline \multirow[t]{3}{*}{ Lung } & IMRT & 2.6 & 1.1 & 5.2 & 8.8 & 1.8 \\
\hline & VMAT & 2.8 & 0.1 & 5.5 & 10.1 & 2.4 \\
\hline & TOMO & 6.9 & 3.0 & 11.6 & 16.5 & 6.1 \\
\hline \multirow[t]{3}{*}{ Stomach } & IMRT & 10.5 & 30.7 & 49.3 & 26.0 & 1.7 \\
\hline & VMAT & 23.4 & 30.5 & 49.5 & 30.3 & 7.3 \\
\hline & TOMO & 28.3 & 46.7 & 53.3 & 43.0 & 13.5 \\
\hline \multirow[t]{3}{*}{ Normal liver } & IMRT & 41.0 & 20.1 & 45.2 & 45.7 & 29.3 \\
\hline & VMAT & 42.7 & 18.5 & 38.7 & 54.1 & 30.6 \\
\hline & TOMO & 47.0 & 25.3 & 44.9 & 49.8 & 35.0 \\
\hline \multirow[t]{3}{*}{ Small intestine } & IMRT & 1.3 & 0.4 & 1.9 & 4.8 & 0.7 \\
\hline & VMAT & 1.3 & 0.5 & 1.9 & 4.8 & 1.1 \\
\hline & TOMO & 1.4 & 0.3 & 1.9 & 15.7 & 0.6 \\
\hline \multirow[t]{3}{*}{ Prostate/Ovary } & IMRT & 0.5 & 0.2 & 0.5 & 1.2 & 0.3 \\
\hline & VMAT & 0.4 & 0.1 & 0.5 & 1.0 & 0.3 \\
\hline & TOMO & 0.4 & 0.1 & 0.5 & 0.9 & 0.2 \\
\hline \multirow[t]{3}{*}{ Rectum } & IMRT & 0.3 & 0.1 & 0.4 & 0.9 & 0.2 \\
\hline & VMAT & 0.3 & 0.1 & 0.4 & 0.7 & 0.2 \\
\hline & TOMO & 0.3 & 0.1 & 0.3 & 0.7 & 0.2 \\
\hline
\end{tabular}

The in-field region organs were the lung, stomach, and normal liver. The other organs were out-of-field. The doses of in-field region organs were calculated from the dose-volume histogram, and the doses of out-of-field region organs were measured by RPLGD detectors inside a humanoid phantom. 
important factor to decide the absorbed dose. In the Table 5, only stomach has not directly depended on the PTV size because of the relative position is more important factor in this case. Therefore the normal liver had the highest organ dose of the measured organs. Although TOMO uses twice the total MUs of other modalities, we did not observe any significant difference in organ dose according to modality for any of the out-offield organs. Only patient 4 had a greater small intestine dose with TOMO than with other treatment modalities, but differences in planning caused this increase, not the modality itself. Among the in-field region organs, the lung dose was greater with TOMO than with other modalities for the same reason. Figure 3 presents the DVHs for patients 1, and for the lung (blue), stomach (black) and liver (green). As evident in Figure 3, patient 1 had approximately twice the lung dose for the TOMO plan (solid line) than for the IMRT (dashed) or VMAT (dotted) plans. In addition, patient 4 also had a relatively large PTV, which can lead to greater increases in the small intestine dose and the dose-volume distribution for TOMO than for other modalities. Recently, Howell et al. have reported late effects from in-field and outof-field doses that were sustained during radiation treatment for liver cancer [46]. To obtain in-field and out-of-field doses, they used a DVH and TLD-based dose measurements from a humanoid phantom. The mean doses to the thyroid, stomach, prostate, and rectum were $0.8,17.5,0.2$, and $0.3 \mathrm{cGy} / \mathrm{Gy}_{\mathrm{Rx}}$, which are comparable to the measurements in this study: $0.5 \pm 0.4$, $23.6 \pm 16.5,0.6 \pm 0.4$, and $0.4 \pm 0.3 \mathrm{cGy} / \mathrm{Gy}_{\mathrm{Rx}}$. The error is calculated from the standard deviation from the dose measurement of five patients and size of error is about $70 \%$ of measured value. We expect this error came from the difference of PTV size as mention as above. Therefore, it can be directly compared with Howell et al's result with PTV size information. In addition, our finding are well matched with previous study by Taddei et al. for the site-specific predicted lifetime risk of second malignant neoplasm (SMN) of HCC at 2010 [50]. They have reported the risks of SMN for thyroid, lung, stomach, normal liver, small bowel and prostate as less than $0.1 \%, 2.8 \%, 2.0 \%, 2.9 \%, 1.8 \%$ and $0.1 \%$ which were comparable to our results as less than $0.1 \%, 2.1 \%, 2.8 \%$, $3.0 \%, 1.0 \%$ and $0.1 \%$ for same site. Both results show good agreements at most of organs. To compare the both results directly, we calculated the risks of SMN by using their calculation skim with our measurements. For five patients, the predicted lifetime risks of normal liver were ranged from $2.6 \%$ to $7.2 \%$ and we found the risks of SMN become larger when the PTV size increasing.

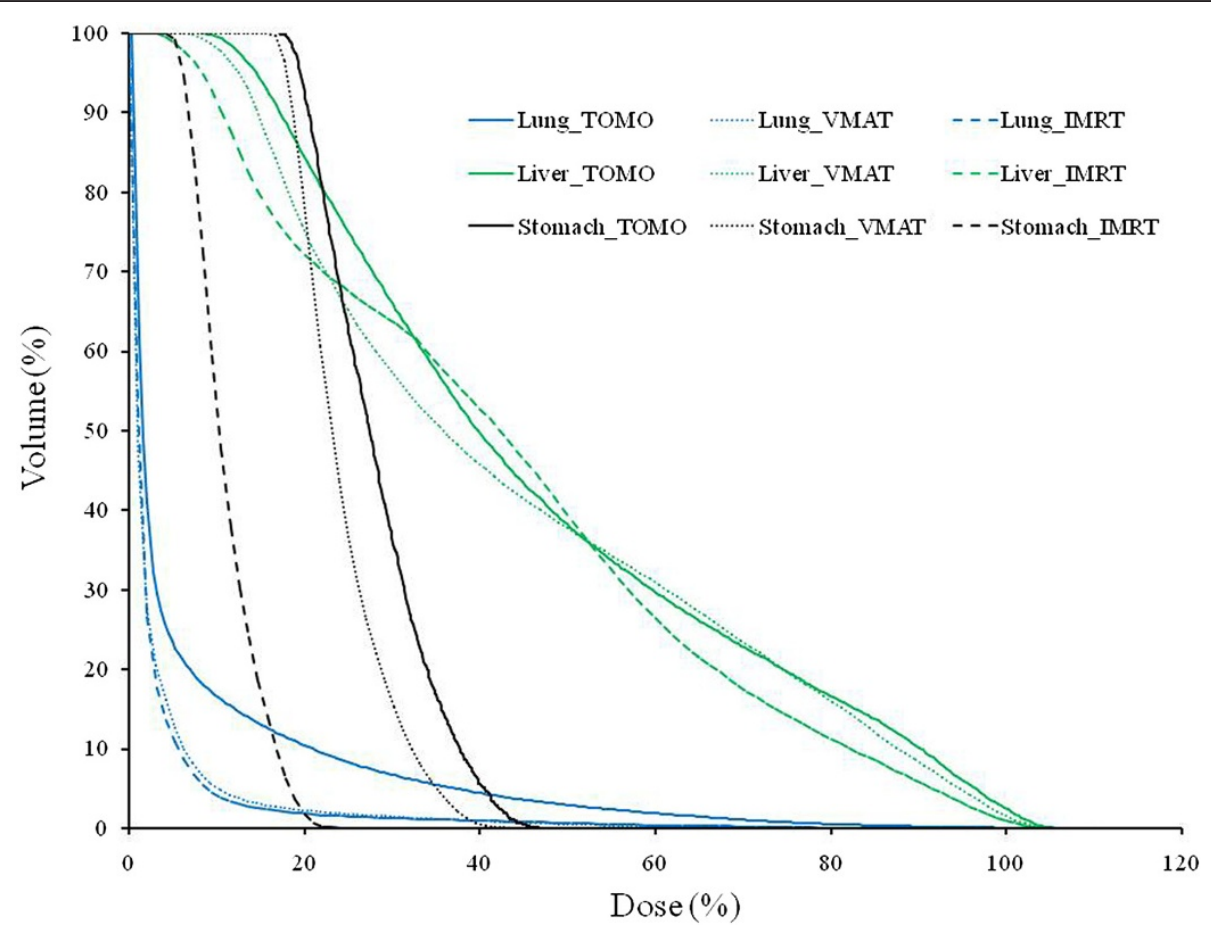

Figure 3 Dose-volume histogram (DVH) for IMRT (dashed), VMAT (dotted), and TOMO (solid line) plans. These histograms include dose-volume information of patient 1 for the lung (blue), normal liver (green), and stomach (black). 
For the absorbed doses of organs in in-field region, the uncertainties were assumed to less than 3\% because the absorbed dose values from primary radiation for IMRT, VMAT and TOMO were based on the dose calculation from the radiation treatment planning system (RTPS). The dose measurement uncertainties of organs at outof-fields region where is mainly contributed by stray radiation was less than 3\% for each RPLGD measurement.

For each of the five patients, Table 3 presents OED measurements (or calculation from DVH) for IMRT, VMAT, and TOMO. The mean OEDs per prescription dose at the thyroid, lung, stomach, normal liver, small intestine, prostate (or ovary), and rectum were 0.26 , $0.65,0.88,0.98,0.87,0.28$, and 0.22 Gy for IMRT; 0.22 , $0.72,1.01,0.99,0.91,0.23$, and 0.18 Gy for VMAT; and $0.21,2.18,0.83,0.87,1.14,0.22$, and 0.18 Gy for TOMO, respectively. (Means were taken over the five patients). The OED decreased as the distance from the in-field region increased. For the OED measurement at out-offield region, the OED differences for three different modalities at each organ were less than $10 \%$ except patient 2. This result conflicts with the findings of a previous study on lung cancer [30]. In this previous study, we reported that TOMO resulted in lower OEDs than IMRT or VMAT, based on estimations of OED for the thyroid, pancreas, bowel, rectum, and prostate. The main difference between these two studies is the measurement setup and treatment site. In the previous study, RPLGDs were positioned on the treatment table without build-up material. In this study, RPLGDs were inserted into the humanoid phantom at each organ position. Because the previous study could not include the maximum out-of-field dose without the build-up material, $6 \mathrm{MV}$ TOMO provided lower OEDs than IMRT or VMAT (which usually use $6 \mathrm{MV}$ photon beam). For infield region, the OED of lung was greater with TOMO than other modalities as shown as Table 3 because the absorbed dose of lung with TOMO was relatively higher than other modalities. Because the OED calculation was based on a plateau-response model which is converged to $1 / \delta$ with high absorbed dose, the OED values of stomach and normal liver were close to 0.83 .

Tables 6 and 7 presents ERR, EAR, and LAR results, which indicate that $59,45,21,27,2,7$ patients, 65,46 ,

Table 6 Excess relative risk (ERR) and excess absolute risk (EAR) for five patients

\begin{tabular}{|c|c|c|c|c|c|c|}
\hline \multirow[t]{2}{*}{ Organ } & \multirow[t]{2}{*}{ Modality\ID } & \multicolumn{5}{|c|}{ ERR (EAR*) } \\
\hline & & 1 & 2 & 3 & 4 & 5 \\
\hline \multirow[t]{3}{*}{ Thyroid } & IMRT & 0.11 & 0.05 & 0.15 & 0.58 & 0.18 \\
\hline & VMAT & 0.08 & 0.05 & 0.12 & 0.49 & 0.18 \\
\hline & TOMO & 0.10 & 0.08 & 0.10 & 0.42 & 0.12 \\
\hline \multirow[t]{3}{*}{ Lung } & IMRT & $0.03(1.47)$ & $0.02(0.50)$ & $0.04(1.76)$ & $2.98(18.22)$ & $0.34(1.01)$ \\
\hline & VMAT & $0.07(1.51)$ & $0.02(0.53)$ & $0.04(1.95)$ & $3.31(22.20)$ & $0.42(1.26)$ \\
\hline & TOMO & $0.91(20.08)$ & $0.39(11.28)$ & $0.52(22.77)$ & $3.76(22.97)$ & $2.53(7.62)$ \\
\hline \multirow[t]{3}{*}{ Stomach } & IMRT & $0.11(9.76)$ & $0.13(7.22)$ & $0.12(8.82)$ & $0.33(6.04)$ & $0.49(5.79)$ \\
\hline & VMAT & $0.44(9.79)$ & $0.13(7.28)$ & $0.12(8.82)$ & $0.33(6.04)$ & $0.79(9.29)$ \\
\hline & TOMO & $0.44(9.79)$ & $0.13(7.35)$ & $0.12(8.82)$ & $0.33(6.04)$ & $0.38(4.48)$ \\
\hline \multirow[t]{3}{*}{ Normal liver } & IMRT & $0.17(6.59)$ & $0.17(3.76)$ & $0.18(5.62)$ & $0.21(1.42)$ & $0.52(1.94)$ \\
\hline & VMAT & $0.44(6.60)$ & $0.17(3.75)$ & $0.18(5.64)$ & $0.22(1.48)$ & $0.53(2.00)$ \\
\hline & TOMO & $0.46(6.95)$ & $0.20(4.46)$ & $0.19(5.95)$ & $0.23(1.56)$ & $0.27(1.00)$ \\
\hline \multirow[t]{3}{*}{ Small intestine } & IMRT & $0.27(5.16)$ & $0.12(1.47)$ & $0.38(6.08)$ & $0.72(4.82)$ & $0.20(0.85)$ \\
\hline & VMAT & $0.33(4.85)$ & $0.13(1.65)$ & $0.38(6.20)$ & $0.72(4.80)$ & $0.28(1.22)$ \\
\hline & TOMO & $0.37(5.35)$ & $0.10(1.20)$ & $0.38(6.05)$ & $1.24(8.31)$ & $0.27(0.71)$ \\
\hline \multirow[t]{3}{*}{ Prostate/Ovary } & IMRT & $0.02(0.07)$ & $0.01(0.03)$ & $0.02(0.06)$ & $0.18(0.61)$ & $0.07(0.14)$ \\
\hline & VMAT & $0.10(0.05)$ & $0.01(0.01)$ & $0.02(0.06)$ & $0.15(0.49)$ & $0.06(0.13)$ \\
\hline & TOMO & $0.11(0.06)$ & $0.01(0.01)$ & $0.02(0.05)$ & $0.14(0.46)$ & $0.05(0.11)$ \\
\hline \multirow[t]{3}{*}{ Rectum } & IMRT & $0.07(1.36)$ & $0.04(0.44)$ & $0.09(1.49)$ & $0.18(1.20)$ & $0.06(0.25)$ \\
\hline & VMAT & $0.08(1.12)$ & $0.03(0.35)$ & $0.08(1.26)$ & $0.14(0.96)$ & $0.06(0.26)$ \\
\hline & TOMO & $0.09(1.32)$ & $0.03(0.36)$ & $0.07(1.13)$ & $0.14(0.95)$ & $0.05(0.20)$ \\
\hline
\end{tabular}

* EAR: per whole prescribed dose. 
Table 7 Lifetime attributable risk (LAR) for five patients

\begin{tabular}{ccrrrrr}
\hline \multirow{2}{*}{ Organ } & ModalitylID & \multicolumn{5}{c}{ LAR $^{*}$} \\
\cline { 2 - 7 } Lung & & $\mathbf{1}$ & $\mathbf{2}$ & $\mathbf{3}$ & $\mathbf{4}$ & $\mathbf{5}$ \\
\hline \multirow{4}{*}{ Stomach } & IMRT & 4.1 & 3.3 & 6.9 & 220.4 & 18.0 \\
& VMAT & 4.3 & 3.4 & 7.7 & 244.3 & 22.5 \\
& TOMO & 56.4 & 72.6 & 89.6 & 277.9 & 135.3 \\
& IMRT & 27.4 & 46.5 & 34.7 & 73.0 & 102.9 \\
Normal liver & VMAT & 27.5 & 46.9 & 34.7 & 73.0 & 165.1 \\
& TOMO & 27.5 & 47.3 & 34.7 & 73.0 & 79.5 \\
& IMRT & 18.5 & 24.2 & 22.1 & 17.2 & 34.4 \\
Small intestine & VMAT & 18.5 & 24.1 & 22.2 & 17.9 & 35.5 \\
& TOMO & 19.5 & 28.7 & 23.4 & 18.8 & 17.8 \\
& IMRT & 14.5 & 9.5 & 23.9 & 58.4 & 15.1 \\
& VMAT & 13.6 & 10.6 & 24.4 & 58.1 & 21.6 \\
\multirow{3}{*}{ Prostate/Ovary } & TOMO & 15.0 & 7.7 & 23.8 & 100.5 & 12.6 \\
& IMRT & 0.2 & 0.2 & 0.2 & 7.4 & 2.5 \\
& VMAT & 0.1 & 0.1 & 0.2 & 6.0 & 2.4 \\
& TOMO & 0.2 & 0.1 & 0.2 & 5.5 & 2.0 \\
& IMRT & 3.8 & 2.8 & 5.9 & 14.6 & 4.4 \\
Rectum & VMAT & 3.1 & 2.3 & 4.9 & 11.7 & 4.5 \\
& TOMO & 3.7 & 2.3 & 4.5 & 11.5 & 3.6 \\
\hline & & & & & &
\end{tabular}

*LAR: per 10000 persons.

21, 27, 2, 6 patients, and 124, 46, 23, 37, 1, 5 patients per 10,000 person for IMRT, VMAT and TOMO will develop radiation-induced cancers of the lung, stomach, normal liver, small intestine, prostate (or ovary), and rectum in the remainder of the lifetime following radiation treatment for HCC. TOMO has relatively higher risk at lung and small intestine comparing to other modalities. The sum of LARs for each site from this study indicates that $1.6 \%$, $1.6 \%$ and $2.4 \%$ of patients with HCC will develop radiation-induced cancer in the remainder of the lifetime following radiation therapy (RT) by IMRT, VMAT and TOMO. Brenner et al. (2000) studied the secondary cancer risk in prostate cancer patients and estimated the incidences of extra solid tumors after radiotherapy [51]. They reported, among 17,327 persons at risk, 139 extra solid tumors were estimated to be induced by radiation treatment. This indicates that the sum of LARs due to the prostate radiotherapy is approximately $0.27 \%$ which is less than the risk with HCC treatment. This may be due to the fact that the exposed age is high and the number of organs at risk is few for prostate cancer treatment compared to HCC treatment. This comparison indicates that the LAR value is critically dependent on the site of cancer and the exposed age.

Although the risk of radiogenic cancer is generally proportional to exposed dose, there are non-negligible uncertainties in the risk model such as the uncertainty in the dose-response relationship for carcinogenesis, uncertainty in the model parameter and etc. The latest report on radiation risk suggested that one cannot choose decisively among the several dose-response models based on the empirical data [17]. This means that there might be large inherent uncertainties in the risk estimation. In addition, there is the systematic uncertainty of applying a risk model for a general U.S. population to international liver cancer patients in our study. This implies that further study on the correlation between dose and secondary cancer risk is needed.

\section{Conclusion}

In this study, we compared secondary cancer risks for patients with HCC. We found that the secondary cancer risk in the out-of-field region depends on the distance from the target volume and the target volume size. Of all the organs that were considered, the lung was subject to the highest risk of radiation-induced cancer after HCC RT.

\section{Consent}

Written informed consent was obtained from the patient for the publication of this report and accompanying images.

\section{Competing interests}

The authors declare that they have no competing interests.

\section{Authors' contributions}

DWK and MY designed and wrote a first version of the manuscript for this research. WKC, SB and SH provided the patient data and clinical support. KC, $\mathrm{CSH}$, and DOS participated in tomotherapy planning and measurement. YKL, SBL, DHS and SYP contributed in IMRTNMAT planning and measurement. SHP, HHL and JS participated in the measurements, detector calibrations and EUD calculation. All authors read and approved the final manuscript

\section{Acknowledgment}

This work was supported by the General Researcher Program (NRF-2012R1A1A2003174); the Nuclear Safety Research Program (Grant No. 1305033) through the Korea Radiation Safety Foundation (KORSAFe) and the Nuclear Safety and Security Commission (NSSC); the Radiation Safety Program (2011-31115); and Radiation Technology Development Program (2013M2A2A4027117), Republic of Korea.

\section{Author details}

${ }^{1}$ Department of Radiation Oncology, KyungHee University Hospital at Gangdong, Seoul, Korea. ${ }^{2}$ Deparment of Radiation Oncology, Samsung Medical Center, Seoul, Korea. ${ }^{3}$ Department of Radiation Oncology, KyungHee University Medical Center, Seoul, Korea. ${ }^{4}$ Department of Neurosurgery, Ulsan University Hospital, Ulsan, Korea. ${ }^{5}$ Proton Therapy Center, McLaren Cancer Institute, Flint, USA. 'Proton Therapy Center, National Cancer Center, Ilsan, Korea. ${ }^{7}$ Department of Radiological Science, College of Health Science, Korea University, Jeongneung 3-dong, Seongbuk-gu, Seoul, Korea.

Received: 10 September 2013 Accepted: 17 March 2014 Published: 8 May 2014 


\section{References}

1. Okuda K, Ohtsuki T, Obata H, Tomimatsu M, Okazaki N, Hasegawa H, Nakajima Y, Ohnishi K: Natural history of hepatocellular carcinoma and prognosis in relation to treatment. Study of 850 patients. Cancer 1985, 56(4):918-928.

2. Song TJ, Ip EW, Fong Y: Hepatocellular carcinoma: current surgical management. Gastroenterology 2004, 127(5 Suppl 1):S248-S260.

3. Lau WY, Lai EC: Hepatocellular carcinoma: current management and recent advances. Hepatobiliary Pancreat Dis Int: HBPD INT 2008, 7(3):237-257.

4. Lencioni RA, Allgaier HP, Cioni D, Olschewski M, Deibert $P$, Crocetti L, Frings H, Laubenberger J, Zuber I, Blum HE, Bartolozzi C: Small hepatocellular carcinoma in cirrhosis: randomized comparison of radio-frequency thermal ablation versus percutaneous ethanol injection. Radiology 2003, 228(1):235-240.

5. Lin SM, Lin CJ, Lin CC, Hsu CW, Chen YC: Radiofrequency ablation improves prognosis compared with ethanol injection for hepatocellular carcinoma $<$ or $=4 \mathrm{~cm}$. Gastroenterology 2004, 127(6):1714-1723.

6. Cheng JC, Chuang VP, Cheng SH, Huang AT, Lin YM, Cheng TI, Yang PS, You DL, Jian JJ, Tsai SY, Sung JL, Horng CF: Local radiotherapy with or without transcatheter arterial chemoembolization for patients with unresectable hepatocellular carcinoma. Int J Radiat Oncol Biol Phys 2000, 47(2):435-442

7. Hawkins MA, Dawson LA: Radiation therapy for hepatocellular carcinoma: from palliation to cure. Cancer 2006, 106(8):1653-1663.

8. Llovet JM, Bruix J: Systematic review of randomized trials for unresectable hepatocellular carcinoma: Chemoembolization improves survival. Hepatology 2003, 37(2):429-442.

9. Emami B, Lyman J, Brown A, Coia L, Goitein M, Munzenrider JE, Shank B, Solin $L$, Wesson M: Tolerance of normal tissue to therapeutic irradiation. Int J Radiat Oncol Biol Phys 1991, 21(1):109-122.

10. Hoskin PJ: Advances in IMRT: a clinical perspective. Lancet Oncol 2000, $1: 74$.

11. Low DA, Mutic S: A commercial IMRT treatment-planning dosecalculation algorithm. Int J Radiat Oncol Biol Phys 1998, 41(4):933-937.

12. Teh BS, Woo SY, Butler EB: Intensity modulated radiation therapy (IMRT): a new promising technology in radiation oncology. Oncologist 1999, 4(6):433-442.

13. Vaarkamp J, Krasin M: Reduction of target dose inhomogeneity in IMRT treatment planning using biologic objective functions. Int J Radiat Oncol Biol Phys 2001, 49(5):1518-1520.

14. Ahamad A, Stevens CW, Smythe WR, Liao Z, Vaporciyan AA, Rice D, Walsh G, Guerrero T, Chang J, Bell B, Komaki R, Forster K: Promising early local control of malignant pleural mesothelioma following postoperative intensity modulated radiotherapy (IMRT) to the chest. Cancer J 2003 9(6):476-484.

15. Wieland P, Dobler B, Mai S, Hermann B, Tiefenbacher U, Steil V, Wenz F, Lohr F: IMRT for postoperative treatment of gastric cancer: covering large target volumes in the upper abdomen: a comparison of a stepand-shoot and an arc therapy approach. Int J Radiat Oncol Biol Phys 2004 59(4):1236-1244

16. Malhotra HK, Raina S, Avadhani JS, de Boer S, Podgorsak MB: Technical and dosimetric considerations in IMRT treatment planning for large target volumes. J Appl Clin Med Phys/American College of Medical Physics 2005, 6(4):77-87.

17. Council NR: Committee to Assess Health Risks from Exposure to Low Levels of lonizing Radiation, Health Risks from Exposure to Low Levels of lonizing Radiation (BEIR VII Phase 2). In Washington, DC: National Academies Press; 2006

18. Petersen JB, Lassen Y, Hansen AT, Muren LP, Grau C, Hoyer M: Normal liver tissue sparing by intensity-modulated proton stereotactic body radiotherapy for solitary liver tumours. Acta Oncol 2011, 50(6):823-828.

19. Brahme A, Roos JE, Lax I: Solution of an integral equation encountered in rotation therapy. Phys Med Biol 1982, 27(10):1221-1229.

20. Otto K: Volumetric modulated arc therapy: IMRT in a single gantry arc Med Phys 2008, 35(1):310-317.

21. Yu CX: Intensity-modulated arc therapy with dynamic multileaf collimation: an alternative to tomotherapy. Phys Med Biol 1995, 40(9):1435-1449.

22. Welsh JS, Patel RR, Ritter MA, Harari PM, Mackie TR, Mehta MP: Helical tomotherapy: an innovative technology and approach to radiation therapy. Technol Cancer Res T 2002, 1(4):311-316.
23. Mackie TR: History of tomotherapy. Phys Med Biol 2006, 51(13):R427-R453.

24. Cao D, Holmes TW, Afghan MK, Shepard DM: Comparison of plan quality provided by intensity-modulated arc therapy and helical tomotherapy. Int J Radiat Oncol Biol Phys 2007, 69(1):240-250.

25. Galinski M, Racine SX, Bossard AE, Fleyfel M, Hamza L, Bouchemal N, Adne $F$, Le Moyec L: Detection and follow-up, after partial liver resection, of the urinary paracetamol metabolites by proton NMR spectroscopy. Pharmacology 2014, 93(1-2):18-23.

26. Jeong H, Lee SB, Yoo SH, Lim YK, Kim TH, Park S, Chai GY, Kang KM, Shin D: Compensation method for respiratory motion in proton treatment planning for mobile liver cancer. J Appl Clin Med Phys / American College of Medical Physics 2013, 14(2):4055

27. Matsuzaki Y, Tanaka N, Chiba T: [Efficacy of proton irradiation for HCC]. Nihon Rinsho Jpn J Clin Med 2001, 59(Suppl 6):659-664.

28. Hall EJ, Wuu CS: Radiation-induced second cancers: the impact of 3D-CRT and IMRT. Int J Radiat Oncol Biol Phys 2003, 56(1):83-88.

29. Yoon M, Ahn SH, Kim J, Shin DH, Park SY, Lee SB, Shin KH, Cho KH: Radiation-induced cancers from modern radiotherapy techniques: intensity-modulated radiotherapy versus proton therapy. Int J Radiat Oncol Biol Phys 2010, 77(5):1477-1485.

30. Kim DW, Chung WK, Shin D, Hong S, Park SH, Park SY, Chung K, Lim YK, Shin D, Lee SB, Lee HH, Yoon M: Risk of second cancer from scattered radiation of intensity-modulated radiotherapies with lung cancer. Radiat Oncol 2013, 8:47

31. Kim S, Min BJ, Yoon M, Kim J, Shin DH, Lee SB, Park SY, Cho S, Kim DH: Secondary radiation doses of intensity-modulated radiotherapy and proton beam therapy in patients with lung and liver cancer. Radiat Oncol: Journal of the European Society for Therapeutic Radiology and Oncology 2011, 98(3):335-339.

32. Howell RM, Hertel NE, Wang Z, Hutchinson J, Fullerton GD: Calculation of effective dose from measurements of secondary neutron spectra and scattered photon dose from dynamic MLC IMRT for $6 \mathrm{MV}, 15 \mathrm{MV}$, and 18 MV beam energies. Med Phys 2006, 33(2):360-368.

33. Williams $\mathrm{PO}$, Hounsell AR: X-ray leakage considerations for IMRT. Br J Radiol 2001, 74(877):98-100.

34. Schneider U, Kaser-Hotz B: A simple dose-response relationship for modeling secondary cancer incidence after radiotherapy. Zeitschrift fur Medizinische Physik 2005, 15(1):31-37.

35. Chiyoda Technol Corporation: Personal monitoring system by glass badge. Tokyo: Chiyoda Technol; 2003.

36. Corporation ATG: RPL Glass Dosimeter/Small Element System Dose Ace. Tokyo: Asahi Glass Co., LTD; 2000.

37. Peisch E, Burgkhardt B, Vilgis M: Photoluminescence dosimetry: progress and present state of art. Radiat Prot Dosim 1990, 33:215-225.

38. Arakia F, Moribe N, Shimonobou T, Yamashita Y: Dosimetric properties of radiophotoluminescent glass rod detector in high-energy photon beams from a linear accelerator and cyber-knife. Med Phys 2004, 31(7):1980-1986.

39. Hsu SM, Yeh SH, Lin MS, Chen WL: Comparison on characteristics of radiophotoluminescent glass dosemeters and thermoluminescent dosemeters. Radiat Prot Dosim 2006, 119(1-4):327-331.

40. KIM DW, Chung W: Characteristic study of radiophotoluminescence glass rod detector for clinical usages: skin and inner body in-vivo verification. J of Korean Phys Soc 2013, 62(3):670-676.

41. Fogliata A, Nicolini G, Vanetti E, Clivio A, Cozzi L: Dosimetric validation of the anisotropic analytical algorithm for photon dose calculation: fundamental characterization in water. Phys Med Bio/ 2006, 51(6):1421-1438.

42. Van Esch A, Tillikainen L, Pyykkonen J, Tenhunen M, Helminen H, Siljamaki S, Alakuijala J, Paiusco M, Lori M, Huyskens DP: Testing of the analytical anisotropic algorithm for photon dose calculation. Med Phys 2006, 33(11):4130-4148.

43. Sterpin E, Salvat F, Olivera G, Vynckier S: Monte Carlo evaluation of the convolution/superposition algorithm of Hi-Art tomotherapy in heterogeneous phantoms and clinical cases. Med Phys 2009, 36(5):1566-1575.

44. Gibbons JP, Smith K Cheek D, Rosen I: Independent calculation of dose from a helical TomoTherapy unit. J Appl Clin Med Phys / American College of Medical Physics 2009, 10(1):2772.

45. Ramsey C, Seibert R, Mahan SL, Desai D, Chase D: Out-of-field dosimetry measurements for a helical tomotherapy system. J App/ Clin Med Phys/American College of Medical Physics 2006, 7(3):1-11.

46. Howell RM, Scarboro SB, Taddei PJ, Krishnan S, Kry SF, Newhauser WD: Methodology for determining doses to in-field, out-of-field and partially 
in-field organs for late effects studies in photon radiotherapy. Phys Med Biol 2010, 55(23):7009-7023.

47. Howell RM, Scarboro SB, Kry SF, Yaldo DZ: Accuracy of out-of-field dose calculations by a commercial treatment planning system. Phys Med Biol 2010, 55(23):6999-7008.

48. Davidson MT, Blake SJ, Batchelar DL, Cheung P, Mah K: Assessing the role of volumetric modulated arc therapy (VMAT) relative to IMRT and helical tomotherapy in the management of localized, locally advanced, and post-operative prostate cancer. Int I Radiat Oncol Biol Phys 2011, 80(5):1550-1558.

49. Foroudi F, Wilson L, Bressel M, Haworth A, Hornby C, Pham D, Cramb J, Gill S, Tai KH, Kron T: A dosimetric comparison of 3D conformal vs intensity modulated vs volumetric arc radiation therapy for muscle invasive bladder cancer. Radiat Oncol 2012, 7:111.

50. Taddei PJ, Howell RM, Krishnan S, Scarboro SB, Mirkovic D, Newhauser WD: Risk of second malignant neoplasm following proton versus intensitymodulated photon radiotherapies for hepatocellular carcinoma. Phys Med Biol 2010, 55(23):7055-7065.

51. Brenner DJ, Curtis RE, Hall EJ, Ron E: Second malignancies in prostate carcinoma patients after radiotherapy compared with surgery. Cancer 2000, 88(2):398-406

doi:10.1186/1748-717X-9-109

Cite this article as: Kim et al:: Risk of secondary cancers from scattered radiation during intensity-modulated radiotherapies for hepatocellular carcinoma. Radiation Oncology 2014 9:109.

\section{Submit your next manuscript to BioMed Central and take full advantage of:}

- Convenient online submission

- Thorough peer review

- No space constraints or color figure charges

- Immediate publication on acceptance

- Inclusion in PubMed, CAS, Scopus and Google Scholar

- Research which is freely available for redistribution 